\title{
Acoustic Emission Study of Plastic Instabilities in AlSi1MgMn
}

\author{
O. Molnárová*, P. Dobroñ and F. Chmelík \\ Charles University in Prague, Faculty of Mathematics and Physics, Department of Physics of Materials, \\ Ke Karlovu 5, 12116 Prague 2, Czech Republic
}

\begin{abstract}
The influence of the strain rate and heat treatment on the occurrence of plastic instabilities in a cast AlSi1MgMn alloy was studied. The samples were uniaxially loaded in compression at various strain rates and at room temperature. The tests were done with concurrent acoustic emission monitoring and the acoustic emission parameters are correlated to the microstructure and to the stress-strain curves in order to better understand the patterns of plastic deformation. All samples exhibited the Portevin-Le Chatelier effect of different types, dependently on the heat treatment and the applied strain rate. The occurrence of the Portevin-Le Chatelier effect is manifested by acoustic emission signals with high amplitudes. Statistical analysis of the acoustic emission signals shows the power-law probability distribution.
\end{abstract}

DOI: $10.12693 /$ APhysPolA.128.801

PACS: 43.40.Le, 81.40.Lm, 62.20.F-, 46.32.+x

\section{Introduction}

The AlSiMgMn alloys, due to their high strength and good corrosion resistance, belong to high performance materials used in construction and transportation. Despite their great physical properties, some AlSiMgMn alloys exhibit under certain circumstances plastic instabilities, which can evolve characteristic striations due to localisation of deformation bands. The respective localization of plastic deformation can significantly deteriorate mechanical properties of the material. In order to improve the reliability of the machine parts produced from these alloys, understanding the degradation processes which can occur during their fabrication and service is definitely required.

The above mentioned plastic instability is referred to the Portevin-Le Chatelier (PLC) effect. The PLC effect manifests as a macroscopic, spatio-temporal instability of plastic deformation, which is characteristic of negative strain rate sensitivity of the deformation stress. Localized strain events in the material cause repeated stress fluctuations on the deformation curve, reflecting a cooperative character of dislocation motion during plastic deformation [1].

A frequently used tool in the investigation of plastic deformation is the acoustic emission (AE) technique. Events like crack nucleation and propagation, mechanical twinning and dislocation motion, which cause sudden local irreversible changes within the material structure, are accompanied with a strong $\mathrm{AE}$ activity. Chmelik et al. $[2,3]$ reported a correlation between the PLC stress drops and the AE activity. It was also shown that each serration on deformation curve corresponds to the movement of a huge amount of dislocations and their cooperative movement produce frequently a strong $\mathrm{AE}$ signal.

*corresponding author; e-mail: mopersze@gmail.com
Recent studies of plastic deformation [4-8] have proven an avalanche-like nature of plastic processes which is characterised by a scale invariance through the powerlaw distribution of measured variables indicating the selforganisation of dislocations. A power-law distribution (PLD) of the probability density, $P\left(E_{\mathrm{AE}}\right) \sim E_{\mathrm{AE}}^{-\alpha}$ was found for the energy of $\mathrm{AE}$ events $\left(E_{\mathrm{AE}}\right)$ either these events were caused by dislocation glide, twinning or by the PLC effect $[5,7]$. The result indicates the intermittent character of the collective motion of crystal defects.

In the present paper, the presence of the self-organised criticality in dislocation dynamics is examined with the help of the power-law analysis. Furthermore, the effect of the threshold voltage set up on the evaluation of $\mathrm{AE}$ events is investigated. The goal of the paper is to study the influence of the deformation parameters, the heat treatment time and the applied strain rate on the occurrence of PLD of $E_{\mathrm{AE}}$. It was shown in [4] that the distributions of the squared amplitude $A^{2}$ reflect the statistics of the energy dissipated by viscoplastic deformation during an event and therefore this approach will be used in our work.

\section{Experimental procedure}

The chemical composition of AlSi1MgMn (AA6082) alloy is given in the Table. Compression specimens with a gauge of $(23.5 \times 11.5 \times 12) \mathrm{mm}^{3}$ were machined from an extruded round bar with a diameter of $60 \mathrm{~mm}$. The deformation axis was parallel to the extrusion direction. The specimens were heat treated for 1 and $4 \mathrm{~h}$ at $530^{\circ} \mathrm{C}$ and quenched into water in order to obtain a stress released condition with a relative low dislocation density. Uniaxial compression tests were performed in a universal testing machine Instron 5882 at room temperature and at constant strain rates of $10^{-3} \mathrm{~s}^{-1}$ and $10^{-4} \mathrm{~s}^{-1}$. The specimens will be hereafter called as $4 \mathrm{~h} \_10^{-3}, 1 \mathrm{~h} \_10^{-4}$ and $4 \mathrm{~h} \_10^{-4}$, respectively. Compression tests were performed up to the stress of $580 \mathrm{MPa}$ and the sampling frequency of the testing machine was $20 \mathrm{~Hz}$. 
TABLE

The chemical composition of the AlSi1MgMn alloy [10].

\begin{tabular}{c|c|c|c|c|c|c|c|c}
\hline \hline element & $\mathrm{Si}$ & $\mathrm{Mg}$ & $\mathrm{Mn}$ & $\mathrm{Fe}$ & $\mathrm{Cr}$ & $\mathrm{Cu}$ & $\mathrm{Zn}$ & $\mathrm{Ti}$ \\
\hline wt.\% & 1.01 & 0.84 & 0.66 & 0.17 & 0.16 & 0.07 & 0.03 & 0.03
\end{tabular}

The AE measurements were performed by a computer controlled system DAKEL-IPL-4 (producer DAKEL-ZD Rpety, Czech Republic), which allows for continuous storage of $\mathrm{AE}$ signals with $2 \mathrm{MHz}$ sampling frequency. The AE signals were detected with the help of a miniaturized piezoelectric transducer MICRO 2006 (DAKEL-ZD Rpety) with a diameter of $3.4 \mathrm{~mm}$ and operating in the frequency band of $100-600 \mathrm{kHz}$. The transducer was attached to the specimen surface and silicon grease was used to improve the contact between the sensor and the specimen. To keep a high ratio between the AE signal and noise, a preamplifier of $35 \mathrm{~dB}$ was used. The full scale of 12 -bit $\mathrm{A} / \mathrm{D}$ converter was $\pm 2 \mathrm{~V}$. The measured AE data were analysed by the DAKEL-UI software by DAKEL-ZD Rpety. The threshold level for the AE events was set to $0.01 \mathrm{mV}$ and the dead time was $0.70 \mathrm{~ms}$. The minimum and maximum hit length was set to 0.05 and $1000 \mathrm{~ms}$, respectively.

\section{Results}

The correlation of the stress-time curve with the maximum amplitude of the detected $\mathrm{AE}$ events $\left(A_{\max }\right)$ for the $1 \mathrm{~h} \_10^{-4}$ specimen is presented in Fig. 1 . The same correlation for $4 \mathrm{~h} \_10^{-3}$ and $4 \mathrm{~h} \_10^{-4}$ specimens can be found in Figs. 2 and 3, respectively. In all samples, the PLC effect occurs shortly after reaching the macroscopic yield point and it is represented by the stress serrations of various types on deformation curve. In case of specimens deformed at $10^{-4} \mathrm{~s}^{-1}$, the $\mathrm{C}$ type of serrations occurs (Fig. 4a,b) whereas the specimen deformed at $10^{-3} \mathrm{~s}^{-1}$ shows the B type (Fig. 4c).

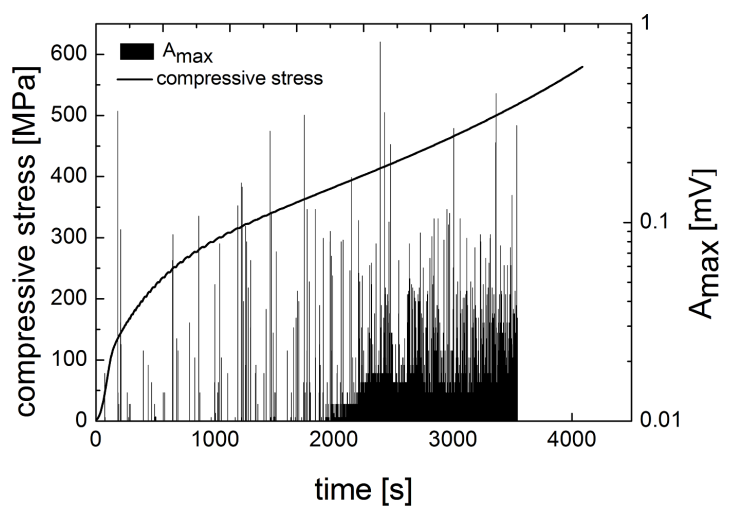

Fig. 1. The stress-time curve for the specimen annealed for $1 \mathrm{~h}$ and deformed at $10^{-4} \mathrm{~s}^{-1}$ correlated with the maximum amplitude of the detected AE events $\left(A_{\max }\right)$.

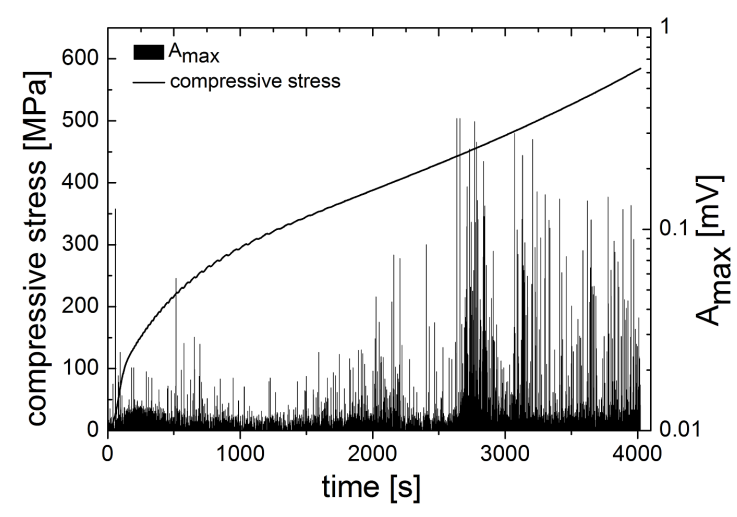

Fig. 2. The stress-time curve for the specimen annealed for $4 \mathrm{~h}$ and deformed at $10^{-4} \mathrm{~s}^{-1}$ correlated with the maximum amplitude of the detected AE events $\left(A_{\max }\right)$

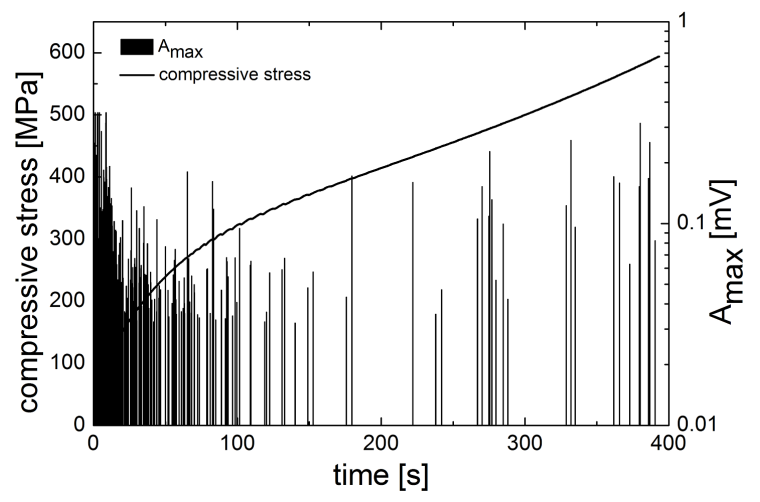

Fig. 3. The stress-time curve for the specimen annealed for $4 \mathrm{~h}$ and deformed at $10^{-3} \mathrm{~s}^{-1}$ correlated with the maximum amplitude of the detected AE events $\left(A_{\max }\right)$.

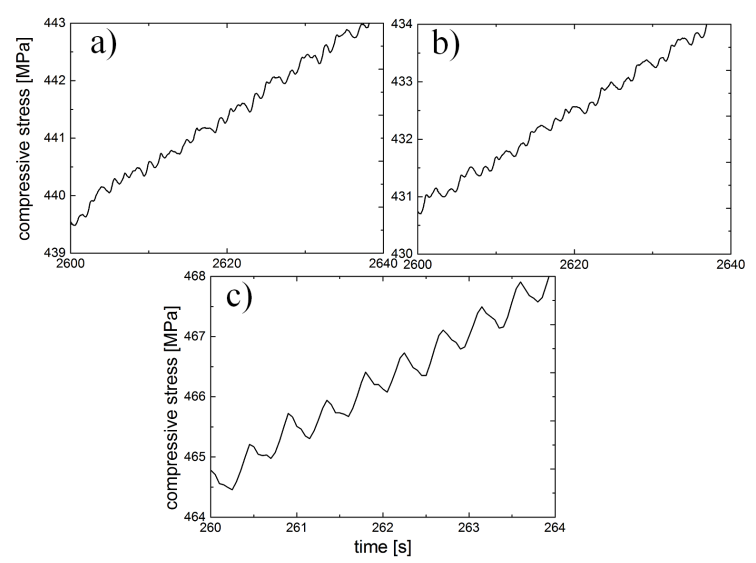

Fig. 4. Details of the stress- time curves from a) Fig. 1, b) Fig. 2, c) Fig. 3 . 
The plastic deformation was accompanied by a strong AE activity. In $1 h_{-} 10^{-4}$ and $4 h_{-} 10^{-4}$ specimens, the AE sources were especially active $\overline{\text { during }}$ the second half of the deformation test, whereas the $4 \mathrm{~h}{ }_{1} 10^{-3}$ specimen exhibited a strong AE activity at the early stage of the test.

The power-law analysis of AE signals was performed in order to uncover the power-law probability density distribution of $E_{\mathrm{AE}}$, which is proportional to the squared maximal amplitude of the events $\left(E_{\mathrm{AE}} \sim A_{\max }^{2}\right)$ and to study the occurrence of the self-organised criticality in related collective dislocation dynamics. To check the influence of the parametrization of $\mathrm{AE}$ signals on the results, various threshold voltages for determination of $\mathrm{AE}$ events were used. The dependence of the power-law exponent $\alpha$ on the threshold voltage setup can be seen in Fig. 5 .

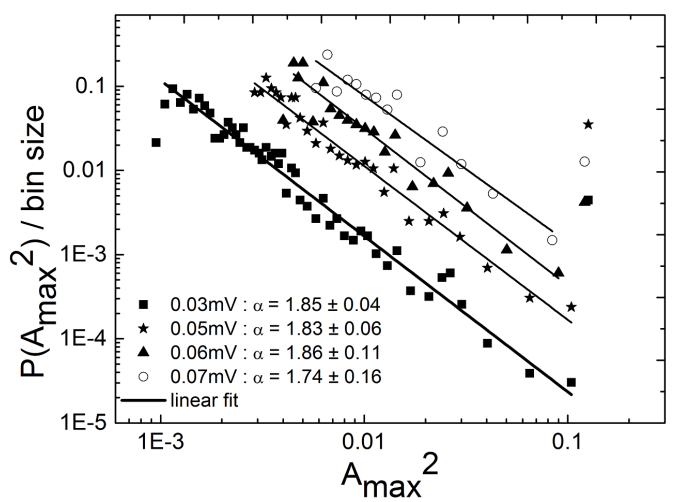

Fig. 5. Dependence of the power-law exponent $\alpha$ on the threshold voltage set up.

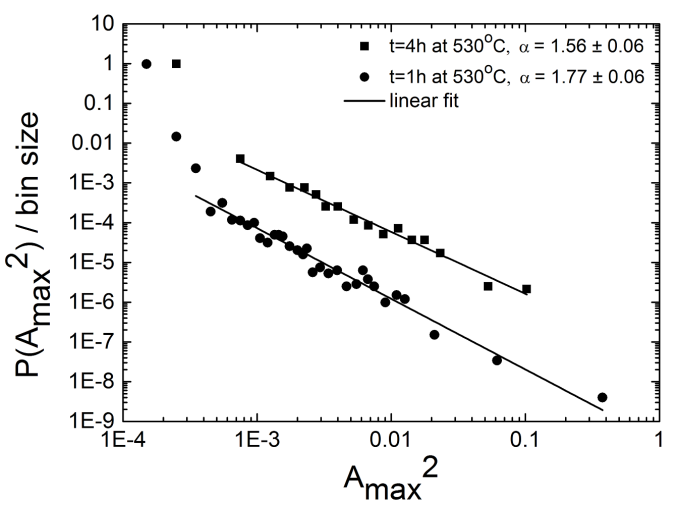

Fig. 6. Dependence of the power-law distribution of the probability density functions on the heat treatment time.

The dependences of the PLD on the heat treatment duration and on the applied strain rate are presented in Figs. 6 and 7, respectively. Linear trend in the loglog graphs can be seen, which means an exponential dependence between the probability of the occurrence of an AE event with a certain squared maximal amplitude.

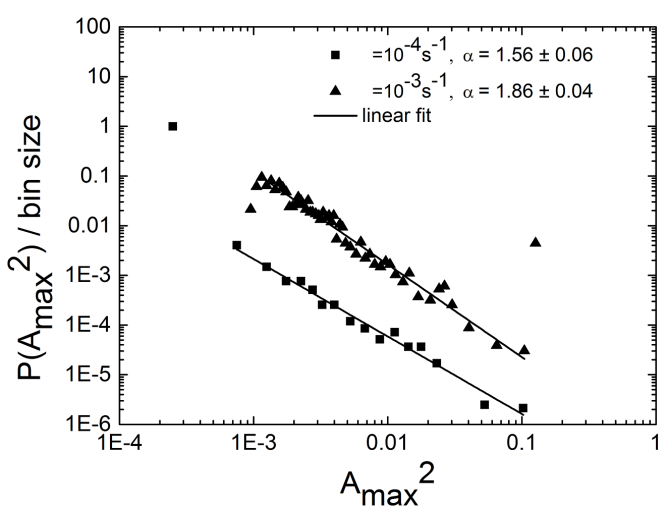

Fig. 7. Dependence of the power-law distribution of the probability density functions on the applied strain rate.

The $A_{\max }^{2}$ from the range of $5 \times 10^{-4}-10^{-1}(\mathrm{mV})^{2}$ was used for the linear fit.

\section{Discussion}

Plastic deformation in the present alloy is realised by a massive dislocation multiplication, by propagation and interaction of dislocations, which are efficient $\mathrm{AE}$ sources $[1,9]$. It was reported in [10] that annealing of such $\mathrm{Al}$ alloy at $530^{\circ} \mathrm{C}$ for $4 \mathrm{~h}$ leads to a low dislocation density due to the recovery processes. Plastic deformation in all samples begins with a massive dislocation multiplication [11] which is followed by the PLC effect. The heat treatment time and applied strain rate significantly influence the activity of the AE sources.

In the $4 \mathrm{~h}-10^{-4}$ specimen, very high number of $\mathrm{AE}$ events with a relative low $A_{\max }$, at early stage of plastic deformation (time interval from 0 to $2000 \mathrm{~s}$ ) can be related to a very low dislocation density. Influence of the initial dislocation density on the parameter $A_{\max }$ during the onset of plastic deformation is clearly seen in the $1 \mathrm{~h} \_10^{-4}$ specimen (Fig. 1). Sessile dislocations act as a barrier for a collective dislocation movement and thereby reduce the number of AE events. The strong AE activity in the $4 \mathrm{~h} 10^{-3}$ specimen (Fig. 2) at the beginning of the test can be related to the increase in the strain rate, which leads to higher dislocation mobility by comparison with the $4 \mathrm{~h}-10^{-4}$ specimen. Furthermore, very high dislocation density at later stage of plastic deformation strongly reduces the AE activity (Fig. 3).

From Fig. 5 it can be seen that the power-law exponent $\alpha$ is independent of the set value of the threshold voltage used for the determination of AE events. Similar results are documented in works [8, 12]. Generally, the main effect of increasing threshold voltage after exceeding the continuous background level is in a reduction of the numbers of points in the dataset.

The investigated alloy shows PLD of $A_{\max }^{2}$ over a range as large as 3 orders of magnitude, independently of the parameters of deformation and the microscopic processes 
which occurred during the deformation. This result confirms the hypothesis that the plastic deformation manifests a universal avalanche-like nature of dislocation motion. The variation of the exponent with the deformation conditions shows that it is not a universal value for all microscopic mechanisms of plastic deformation.

In the present study, the exponents $\alpha$, obtained for the AlSi1MgMn alloy, vary between 1.5 and 1.9. Similar values of the exponent were also obtained for $\mathrm{Cd}$ and $\mathrm{ZnAl}$ single crystals [5]. Load and strain rate controlled tensile tests, and indentation depth measurement on a supersaturated AlZnMg alloy [13] led to the exponents $\alpha$ of 1.86 , which supports the idea about the independence of the exponents of the experimental testing conditions.

Creep testing of polycrystalline ice [6] led to lower values of the exponent (1.3-1.4) and it was attributed to the dual role of grain boundaries. The grain boundaries are obstacles for the dislocations, but the stress from the dislocation pile-ups can activate dislocation sources in neighbouring grains, which leads to a higher probability of larger avalanches.

The statistical analysis of experimental data obtained from polycrystalline AlMg alloy in [7] revealed an unexpected behaviour. It was presented that the statistical distribution of $E_{A E}$ obeys a power law and is like a general property of the intermittency of plastic flow. The power-law exponent $\alpha$ is altered (modified) with strain rate and changed also during the deformation (between 2 and 3 ), but it was possible to find an interval within which it remained unchanged. Varying exponent values were explained by dislocation ageing, influence of grain boundaries and by the folding of AE signals from different sources [7]. The exponent found for an AlMg polycrystalline alloy [7] exceeds 1.5 throughout the deformation, indicating the presence of a large fraction of low amplitude AE events. This difference of the exponents for polycrystalline ice and $\mathrm{AlMg}$ can be explained by the different hardening mechanisms and by the absence of solute hardening and twinning in ice.

For the $\mathrm{B}$ and $\mathrm{C}$ type of serrations, which occur during the tests, a power-law exponent $\alpha$ for the AE energy was found. It confirms the hypothesis of SOC-like behaviour of the system; however the stress drops distribution found in [7] for the B and $\mathrm{C}$ type stress drops had a peak reflecting the existence of a characteristic scale. It is explained by the synchronization of dislocation groups [7].

\section{Conclusion}

Deformation tests were performed on the AlSi1MgMn alloy with concurrent AE measurements. Longer annealing time for specimens deformed at $10^{-4} \mathrm{~s}^{-1}$ led to higher number of the $\mathrm{AE}$ events with lower $A_{\max }$. Increase in the strain rate is reflected in high dislocation mobility and consequently in the high AE activity at the beginning of the test.
The independence of the power-law exponent $\alpha$ of setting the threshold voltage, used for the events extraction from the AE data stream, was shown. The results of the power-law analysis of $A_{\max }^{2}$ confirm the avalanchelike nature of dislocation motion during the compression tests of the alloy. Furthermore, it was shown that the power-law probability distribution of $A_{\max }^{2}$ is independent of microscopic processes of deformation, which are influenced by the heat treatment time of samples and the applied strain rate.

\section{Acknowledgments}

This work was completed within the framework of the research grant P108/11/1267 by the Czech Science Foundation. O.M. is grateful for financial support from the grant SVV-2015-260213 and acknowledges the support from the Grant Agency of Charles University under contract No. 946213.

\section{References}

[1] A. Yilmaz, Sci. Technol. Adv. Mater. 12, 063001 (2011).

[2] F. Chmelık, A. Ziegenbein, H. Neuhäuser, P. Lukáč, Mater. Sci. Eng. A 324, 200 (2002).

[3] F. Chmelık, F.B. Klose, H. Dierke, J. Sachl, H. Neuhauser, P. Lukac, Mater. Sci. Eng. A 462 , 53 (2007).

[4] J. Weiss, J.R. Grasso, M.C. Miguel, A. Vespignani, S. Zapperi, Mater. Sci. Eng. A 309-310, 360 (2001).

[5] T. Richeton, P. Dobroň, F. Chmelik, J. Weiss, F. Louchet, Mater. Sci. Eng. A 424, 190 (2006).

[6] T. Richeton, J. Weiss, F. Louchet, Nat. Mater. 4, 465 (2005).

doi:

[7] Y. Bougherira, D. Entemeyer, C. Fressengeas, N.P. Kobelev, T.A. Lebedkina, M.A. Lebyodkin, J. Phys. Conf. Ser. 240, 012009 (2010).

[8] M.A. Lebyodkin, I.V. Shashkov, T.A. Lebedkina, K. Mathis, P. Dobron, F. Chmelik, Phys. Rev. E 88, 042402 (2013).

[9] K. Mathis, F. Chmelik, in: Acoustic Emission, Ed. W. Sikorski, InTech, Rijeka 2012, p. 23.

[10] V. Očenášek, J. Uhlír, I. Stulíková, B. Smola, in: Metal 2008, 17th Int. Conf. Metallurgy and Materials, Hradec nad Moravici, Tanger, Ostrava 2008, CZ (in Czech).

[11] P. Haasen, B.L. Mordike, Physical Metallurgy, Cambridge University Press, UK 1996.

[12] I. Shashkov, Ph.D. Thesis, Université de Lorraine, Metz 2012.

[13] N.Q. Chinh, T. Gyôri, J. Gubicza, J. Lendvai, T.G. Langdon, MRS Commun. 2, 1 (2012). 